\title{
Spondylometaphyseal dysplasia, Sedaghatian type
}

INSERM

\section{Source}

INSERM. (1999). Orphanet: an online rare disease and orphan drug data base.

Spondylometaphyseal dysplasia, Sedaghatian type. ORPHA:93317

Spondylometaphyseal dysplasia (SEMD), Sedaghatian type is a neonatal lethal form of spondylometaphyseal dysplasia characterized by severe metaphyseal chondrodysplasia,

mild rhizomelic shortness of the upper limbs, and mild platyspondyly. 